\title{
A implementação do Programa Bolsa Família: revisão de literatura ${ }^{1}$
}

\section{The Bolsa Família Program implementation: literature review}

\author{
Fábio Resende de Araújo* \\ Maria Arlete Duarte de Araújo* \\ Fabia Jaiany Viana de Souza ${ }^{* * *}$ \\ Renatha Celiana da Silva Brito ${ }^{* \star *}$
}

\begin{abstract}
Resumo: O objetivo do artigo é revisar estudos que abordam a implementação do Programa Bolsa Família (PBF) categorizando os principais elementos de sua gestão. Realizou-se uma investigação qualitativa com levantamento bibliográfico das bases de dados Biblioteca Cochrane, LILACS, Medline, SciELO, Banco de Teses e Dissertação da Coordenação de Aperfeiçoamento de Pessoal de Nível Superior, Diretório do Domínio Público e Periódicos Capes. Definiuse como critério de escolha trabalhos relativos aos processos gerenciais do programa. Foram selecionados 27 estudos de avaliação da implementação do PBF e classificados dois grupos: ensaios teóricos $(n=10)$ e estudos empíricos $(n=17)$. Entre os estudos teóricos destacam-se três categorias de estudos: coordenação intergovernamental, coordenação intersetorial e avaliação e monitoramento e, nos estudos empíricos, os destaques foram: as categorias de articulação intersetorial, eficácia na implementação pelos municípios e monitoramento/avaliação pelo Indice de Gestão Descentralizada. Conclui-se
\end{abstract}

\footnotetext{
${ }^{1}$ Este artigo foi derivado da tese de doutorado do primeiro autor (ARAÚJO, 2015) com contribuições dos demais autores na sua versão final.

* Doutor e Mestre em Administração pela Universidade Federal do Rio Grande do Norte (UFRN). Possui Graduação em Nutrição pela UFRN. Professor Adjunto da Universidade Federal do Rio Grande do Norte atuando no Departamento de Administração Pública e Gestão Social. E-mail: resende_araujo@hotmail.com.

** Doutora em Administração ( FGV/SP); mestrado em Administração pela UFPB e Graduação em Administração pela Universidade Federal de Sergipe. Pós-doutorado na Universidade Pompeu Fabra, em Barcelona -Espanha. Atualmente é professora Titular da Universidade Federal do Rio Grande do Norte. E-mail: mariaarlete1956@gmail.com.

*** Doutora em Ciências Contábeis pela Universidade Federal da Paraíba. Mestre em Ciências Contábeis pelo Programa Multi-institucional e Inter-regional UnB/UFPB/UFRN. Graduada em Ciências Contábeis pela Universidade Federal do Rio Grande do Norte. Contadora do Instituto Federal de Educação, Ciência e Tecnologia do Rio Grande do Norte. E-mail: fabiajaiany@yahoo.com.br

**** MesMestre em Saúde Coletiva pelo Programa de Pós Graduação em Saúde Coletiva (UFRN). Especialista em Ciências e Tecnologia de Alimento (IFRN). Pós graduanda em Saúde da Família pela FACISA/UFRN. Nutricionista pela UFRN. E-mail: renathacelianaa@hotmail.com
}

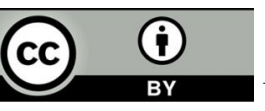


que, apesar do PBF ser um dos programas mais relevantes da política social brasileira, a produção acadêmica acerca de sua implementação apresenta lacunas, tais como: déficit de pesquisas sobre a gestão na região Nordeste e atuação dos governos estaduais.

Palavras-chave: Programa Bolsa Família. Transferência de Renda Condicionada. Coordenação Intergovernamental.

\begin{abstract}
The objective is to review studies that addressed the implementation of the Bolsa Família Program (PBF), categorizing the main elements of its management. A qualitative research was carried out, with a bibliographic survey based on the databases Cochrane Library, LILACS, Medline, SciELO, Thesis Bank and Dissertation of the Coordination for the Improvement of Higher Education Personnel, Public Domain Directory and the Periodicals Capes. With a criterion for choosing works that deal with the program's management processes, 27 studies were selected, classifying them in two groups: theoretical essays $(n=10)$ and empirical studies $(n=17)$ to evaluate the implementation of the PBF. Among the theoretical studies, three categories of studies stand out: intergovernmental coordination, intersectoral coordination and evaluation and monitoring, while in the empirical studies: the categories of intersectoral articulation, effectiveness in the implementation by the municipalities and monitoring / evaluation by the Decentralized Management Index. We conclude that, despite the fact that the PBF is one of the most relevant programs of Brazilian social policy, academic production regarding its implementation has gaps, such as research on management in the Northeast region and the performance of state governments.
\end{abstract}

Keywords: Bolsa Familia Program. Cash Transfer Conditional. Intergovernmental coordination.

Recebido em: 26/11/2019. Aceito em: 07/06/2021

\title{
Introdução
}

O debate em torno das políticas sociais no Brasil passou a se intensificar nas décadas posteriores à Constituição Federal de 1988. Nos anos 2000, os Programas de Transferência Condicionada de Renda (PTRC) ganharam destaque na agenda pública nacional como estratégia para garantia de direitos básicos para a cidadania e fortalecimento econômico do mercado interno. Duas décadas depois da criação dos primeiros PTRC no Brasil se amplia o debate sobre as reais capacidades do Estado (em todos os seus níveis de governo) para implementar as ações da principal política social do país: o Programa Bolsa Família (PBF).

O Programa está estruturado em três eixos: "Inclusão Produtiva", "Garantia de Renda" e "Acesso a Serviços". O PBF pretende promover esses eixos, respectivamente, pelas seguintes ações: 1) Estimulo à inserção em programas denominados "Portas de Saída" como o Pronatec 
(implementado a partir de 2011);2) Repasse Mensal de valor monetário; 3) Condicionamento do recebimento do benefício à presença em serviços básicos de saúde e educação. Pode-se resumir, portanto, as ações do Programa em três dimensões principais: articulação de programas complementares, transferência de renda e acompanhamento das condicionalidades.

Com abrangência nacional, o PBF difere de outras políticas brasileiras pela relação de interdependência entre os entes que o implementam (governos federal, estaduais e municipais), caracterizando-se por uma centralização de concepção e comando das ações principais na União e as demais atividades (cadastros, transferência de beneficio e acompanhamento das condicionalidades) nos governos locais ou subnacionais (BICHIR, 2011). Quanto às suas principais atividades, o PBF desenvolve ações de inserção dos beneficiários na rede de educação e saúde, as condicionalidades.

A forma como o PBF é executado ocorre de modo distinto de outras ações da área de assistência social no que diz respeito à centralização/descentralização das relações dos governos envolvidos e mecanismos usados para atingir seus objetivos. Um dos desafios na implementação do PBF é a assimetria entre os governos locais, tornando imperativo que a coordenação federal do PBF formule uma estratégia para nivelar o seu desempenho de modo a transformar em potencialidades suas características específicas. A centralização adotada no modelo de gerenciamento do Programa pode dificultar ações federais, uma vez que as políticas universais às quais o PBF está conectado operam também sob as possibilidades operacionais dos Estados e Municípios e não apenas da União.

Dada a relevância social e política do PBF, somada à possibilidade de interface das suas ações com outras áreas de conhecimento, há uma intensa produção acadêmica sobre o Programa. Os estudos abordam temas diversos como o perfil geral do Programa, análises comparativas com outros programas de transferência de renda da América Latina, implicações na sucessão presidencial, percepções dos beneficiários, análise do perfil de segurança alimentar e nutricional dos beneficiários e estudos que tratam da avaliação e monitoramento. $\mathrm{O}$ interesse deste artigo se concentra neste último grupo de pesquisas.

Os estudos que tratam da avaliação de políticas públicas podem ser divididos em dois grandes grupos conforme classificação de Draibe (2001) e Subirats (1994): avaliação de impacto e avaliação de implementação. Araújo (2012) indica a avaliação de implementação como uma subárea da pesquisa avaliativa de política representada pela avaliação de processo. Segundo Silva e Melo (2000) a avaliação que ocorre nessa fase pode ser divida de acordo com o seu objetivo em avaliação de eficácia ou de eficiência.

O PBF tem uma relevante produção acadêmica sobre seus impactos, sendo que os principais efeitos investigados recaem sobre os impactos nas condições de pobreza e vida, condições de saúde, desempenho escolar e oferta de trabalho. Igualmente importante são os estudos de implementação, pois os impactos sociais que justificam a formulação do programa só se concretizarão com um Programa bem implementado.

Os estudos que tratam da implementação do PBF são constituídos por ensaios teóricos e estudos empíricos. Os ensaios teóricos descrevem o Programa, apontam determinantes da gestão e problematizam a coordenação intergovernamental intersetorial e a avaliação/monitoramento do mesmo. Já nos estudos empíricos, o foco é a implementação do Programa em diversas localidades do país sob a forma de estudo de caso.

Sendo um Programa muito avaliado a partir de muitas lentes téoricas e metodológicas, este artigo se propõe a revisar estudos que abordam a implementação do Programa Bolsa Família 
(PBF), categorizando os principais elementos da sua gestão. A pesquisa é relevante pois o conhecimento acumulado possibillita discutir questões centrais da implementação do Programa e refletir sobre seu alcance.

Para dar conta deste objetivo, o artigo se estrutura em quatro tópicos. Além desta Introdução, a segunda seção destina-se a explicitar os procedimentos metodológicos; a terceira sistematiza os achados procurando estabelecer relações entre os mesmos ao tempo em que procura evidenciar as constribuições mais importantes para compreensão da implementação do Programa; e, por fim tece considerações sobre o aprendizado acumulado propiciado pela revisão da literatura e define uma agenda de pesquisa futura.

\section{Metodologia}

A investigação, ocorrida entre março de 2015 e fevereiro de 2016, consistiu de uma consulta às bases de dados Biblioteca Cochrane, LILACS, Medline e SciELO, bem como aos portais de organizações públicas como o Banco de Teses e Dissertação da Coordenação de Aperfeiçoamento de Pessoal de Nível Superior (CAPES), Diretório do Domínio Público e Periódicos Capes. Precedendo qualquer análise, realizou-se um levantamento de trabalhos acadêmicos através dos termos "Programa Bolsa Família" e "Transferência de renda condicionada" e seus correspondentes no idioma inglês e espanhol.

Complementando a busca foram pesquisados documentos oficiais e publicações de temáticas relacionadas em sites das entidades Instituto Brasileiro de Geografia e Estatística (IBGE), Instituto de Pesquisa Econômica Aplicada (IPEA), Ministério de Desenvolvimento Social e Combate à Fome e Ministério da Saúde do Brasil e World Health Organization (WHO). Também foram pesquisados livros e capítulos de livros publicados sobre o Programa Bolsa Família (PBF).

Em virtude de sua importância e magnitude o Programa é bastante citado. Apenas no Banco de Teses e Dissertação da Coordenação de Aperfeiçoamento de Pessoal de Nível Superior (CAPES) a palavra-chave (Programa Bolsa Família) resultou em 12.267 achados. Em sua maioria, os trabalhos apenas citavam o Programa no texto. As diferentes bases também apresentavam os mesmos trabalhos a partir de suas diferentes indexações.

Por meio da leitura dos títulos e resumos foram selecionados todos os trabalhos que tratavam do PBF como objeto principal de análise, excluindo-se aqueles em que o mesmo apenas era citado e aparecia de modo acessório no título ou resumo do trabalho. Também foram excluídos trabalhos repetidos, em que um trabalho original (tese ou dissertação) resultou em artigos ou capítulos de livros, optando-se sempre pela fonte primária de informação.

Todos os estudos selecionados na etapa anterior foram analisados integralmente e tiveram suas referências revisadas, visando à identificação de outros trabalhos relacionados ao tema e que, por ventura, não houvessem sido identificados pela busca eletrônica. Nesta etapa foram selecionados 85 publicações. As análises foram realizadas em quatro etapas, conforme detalha a Figura 1, tendo como objetivo principal a análise crítica e sistemática dos estudos empíricos de implementação do Programa. 
Figura 1 - Esquema de análise da revisão de literatura sobre implementação do Programa Bolsa Família, Brasil 2016

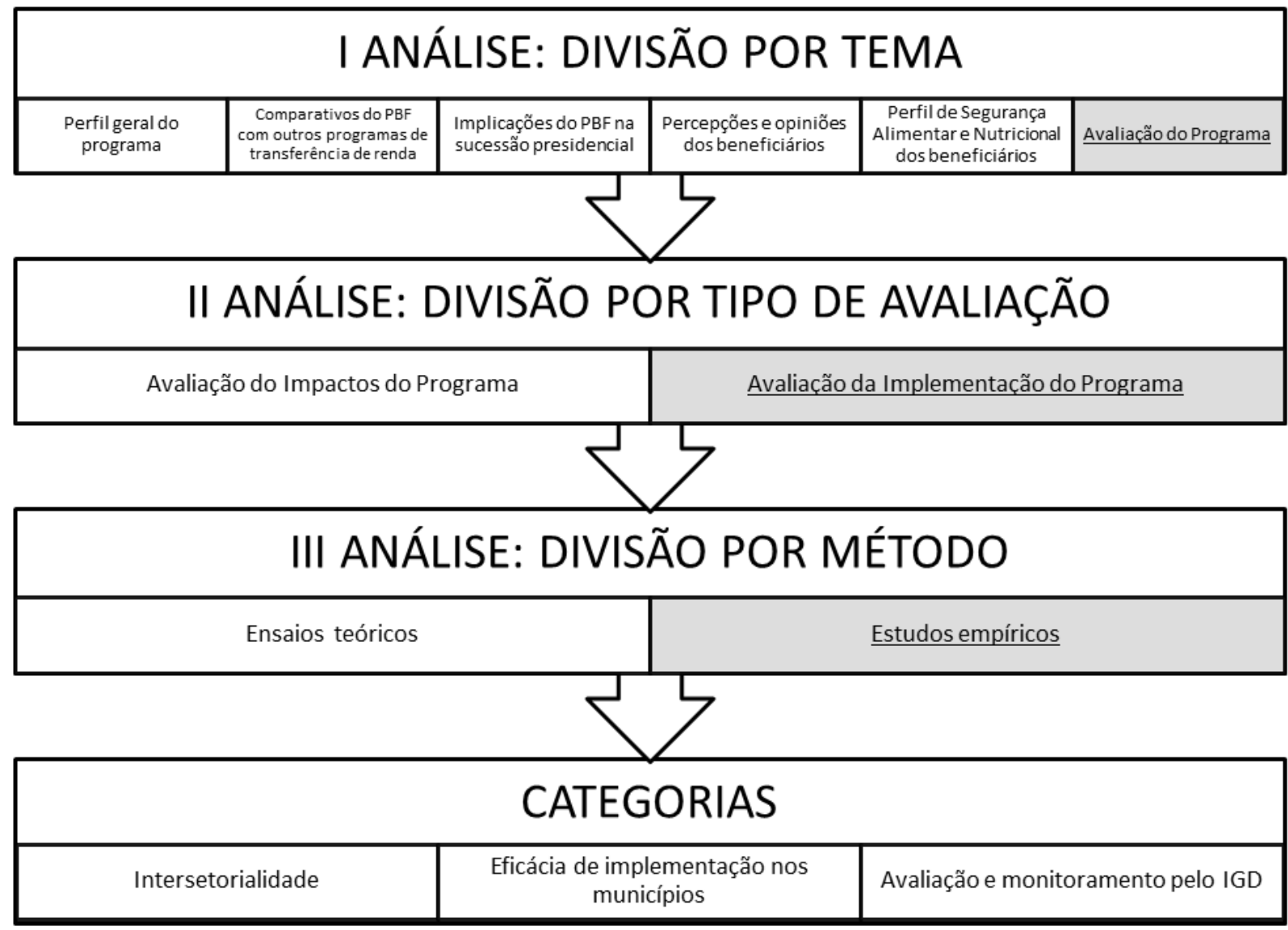

Fonte: Os autores, com base na pesquisa, 2016.

A primeira análise objetivou a divisão pelos temas que o Programa é abordado. Dado a sua complexidade o PBF é pesquisado por diversas áreas do conhecimento. Nessa primeira etapa o esforço foi identificar os grandes temas tratados pelas pesquisas onde o PBF foi investigado para identificar os estudos sobre avaliação do Programa.

Os trabalhos foram divididos em 6 grupos conforme descreve a Figura 1: 1) Perfil geral do Programa (n.12); 2) Comparativos com outros programas de transferência de renda (n.3); 3) Implicações do Programa na sucessão presidencial (n.1); 4) Percepções e opiniões dos beneficiários (n.16); 5) Perfil de Segurança Alimentar e Nutricional dos beneficiários (n.7); 6) Avaliação de sua implementação (n.46).

A segunda análise concentrou-se no grupo de estudos sobre a avaliação do PBF que contabilizou 46 estudos. Segundo os autores Draibe (2001) e Subirats (1994), os estudos de avaliação de políticas públicas se dividem, segundo seu objetivo, em dois grandes tipos: I) Avaliação de impacto ou de processo que verifica a relação entre objetivos e meta com impactos e efeitos; II) Avaliação de processo ou de implementação que aprecia a relação entre características e qualidades dos processos e sistemas de sua implementação e os resultados obtidos. A partir dessa classificação os estudos foram agrupados da seguinte forma: 1) Estudos de Avaliação de Impacto do PBF n.19) e 2) Estudos de avaliação de sua implementação (n.27). 
Com o grupo de estudos selecionados foi realizada uma nova subdivisão pelo método utilizado. Foram encontrados 10 ensaios teóricos sobre implementação do PBF e 17 estudos empíricos sobre implementação. Os estudos foram submetidos à análise de conteúdo para encontrar categorías analíticas que agrupassem pontos importantes levantados pela produção acadêmica selecionada.

Nos estudos empíricos as categorias que emergiram foram: coordenação intergovernamental, coordenação intersetorial e avaliação e monitoramento do Programa. Nos estudos empíricos as categorias analíticas foram: articulação intersetorial, eficácia na implementação do PBF pelo municípios e monitoramento/avaliação pelo Índice de Gestão Descentralizada (IGD).

A delimitação realizada sob os critérios descritos possibilitou o acesso a trabalhos com objetivos similares e a reflexão sobre os limites e êxitos que o PBF alcançou ao longo da sua existência, além de permitir identificar em quais temas há lacunas de produção cientifica sobre sua implementação.

\section{Resultados e discussão}

O primeiro grupo de estudos de implementação do PBF (ensaios teóricos) aborda textos que descrevem o Programa e apontam determinantes de sua gestão de modo amplo. Conforme descreve o Quadro 1, destacam-se três categorias de estudos:coordenação intergovernamental, coordenação intersetorial e avaliação e monitoramento. As presentes categorias apontam elementos definidores da gestão do PBF.

Quadro 1 - Ensaios teóricos sobre a implementação do Programa Bolsa Família de acordo com o tema abordado

\begin{tabular}{|c|c|c|c|}
\hline Tema & $\begin{array}{l}\text { Ensaios } \\
\text { teóricos }\end{array}$ & $\begin{array}{l}\text { Fator destacado da } \\
\text { implementação do } \\
\text { programa }\end{array}$ & Título \\
\hline \multirow{3}{*}{ 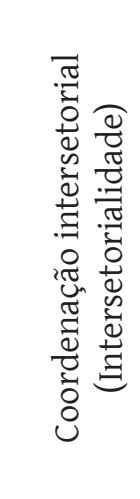 } & $\begin{array}{l}\text { Magalhães e } \\
\text { Bodstein } \\
(2009)\end{array}$ & $\begin{array}{l}\text { Intersetorialidade } \\
\text { das ações das } \\
\text { condicionalidades da } \\
\text { saúde }\end{array}$ & $\begin{array}{l}\text { Avaliação de iniciativas e programas intersetoriais } \\
\text { em saúde: desafios e aprendizados }\end{array}$ \\
\hline & $\begin{array}{l}\text { Quinhões e Fava } \\
\text { (2010) }\end{array}$ & $\begin{array}{l}\text { Intersetorialidade } \\
\text { em programas } \\
\text { complementares }\end{array}$ & $\begin{array}{l}\text { Intersetorialidade e transversalidade: a estratégia } \\
\text { dos programas complementares ao Bolsa Família }\end{array}$ \\
\hline & Silva (2013) & $\begin{array}{l}\text { Intersetorialidade e } \\
\text { nível federal }\end{array}$ & $\begin{array}{l}\text { Mecanismos da construção federal da } \\
\text { intersetorialidade no Programa Bolsa Família: o } \\
\text { papel das burocracias }\end{array}$ \\
\hline
\end{tabular}


conclusão

\begin{tabular}{|c|c|c|c|}
\hline Tema & $\begin{array}{l}\text { Ensaios } \\
\text { teóricos }\end{array}$ & $\begin{array}{l}\text { Fator destacado da } \\
\text { implementação do } \\
\text { programa }\end{array}$ & Título \\
\hline \multirow{6}{*}{ 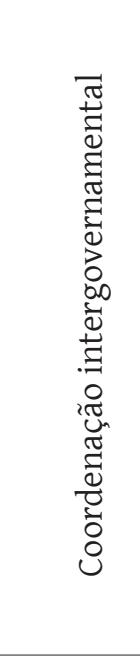 } & Afonso (2006) & Federalismo & $\begin{array}{l}\text { Novos desafios à descentralização fiscal no Brasil: } \\
\text { as políticas sociais e as de transferência de renda. }\end{array}$ \\
\hline & Lício (2004) & Federalismo & $\begin{array}{l}\text { A trajetória dos programas de transferência de } \\
\text { renda no Brasil: o impacto da variável federativa. }\end{array}$ \\
\hline & Mesquita (2006) & Coordenação federativa & $\begin{array}{l}\text { Contradições do processo de implementação de } \\
\text { políticas públicas: uma análise do Programa Bolsa } \\
\text { Família 2003 - } 2006\end{array}$ \\
\hline & $\begin{array}{l}\text { Cavalcante } \\
(2009)\end{array}$ & $\begin{array}{l}\text { Descentralização } \\
\text { governamental }\end{array}$ & $\begin{array}{l}\text { Programa Bolsa Família: descentralização, } \\
\text { centralização ou gestão em redes? }\end{array}$ \\
\hline & $\begin{array}{l}\text { Lício; Mesquita } \\
\text { e Curralero } \\
\text { (2011) }\end{array}$ & $\begin{array}{l}\text { Coordenação } \\
\text { intergovernamental }\end{array}$ & $\begin{array}{l}\text { Desafios para coordenação intergovermental do } \\
\text { Programa Bolsa Família }\end{array}$ \\
\hline & Coutinho (2013) & Capacidades Estatais & $\begin{array}{l}\text { Entre a eficiência e legitimidade: o Bolsa Família } \\
\text { no desafio de consolidação do SUAS }\end{array}$ \\
\hline 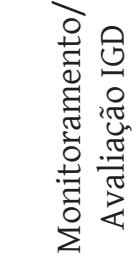 & $\begin{array}{l}\text { Curralero e } \\
\text { Alonso (2011) }\end{array}$ & $\begin{array}{l}\text { Índice de Gestão } \\
\text { Descentralizada (IGD) }\end{array}$ & $\begin{array}{l}\text { O Índice de Gestão Descentralizada (IGD) e o } \\
\text { Sistema de Condicionalidades (SICON) como } \\
\text { ferramentas de gestão intersetorial do Programa } \\
\text { Bolsa Família. }\end{array}$ \\
\hline
\end{tabular}

Fonte: Os autores, com base na pesquisa, 2016.

O segundo grupo trata de estudos empíricos de avaliação da implementação do PBF, onde são problematizadas questões da gestão do Programa em diversas localidades sob a forma de estudo de caso. Para esse grupo procurou-se sistematizar além dos objetivos, os resultados relevantes de sua implementação.

Essa sistematização permitiu compreender quais as potencialidades e limites da gestão na implementação do PBF. Na revisão da literatura emergiram como determinantes de sua implementação as categorias: articulação intersetorial, eficácia na implementação do PBF pelos municípios e monitoramento/avaliação do mesmo pelo IGD, descritas na Figura 2. 
Figura 2 - Categorias e subcategorias dos estudos empíricos sobre a implementação do Programa Bolsa Família, Brasil, 2016
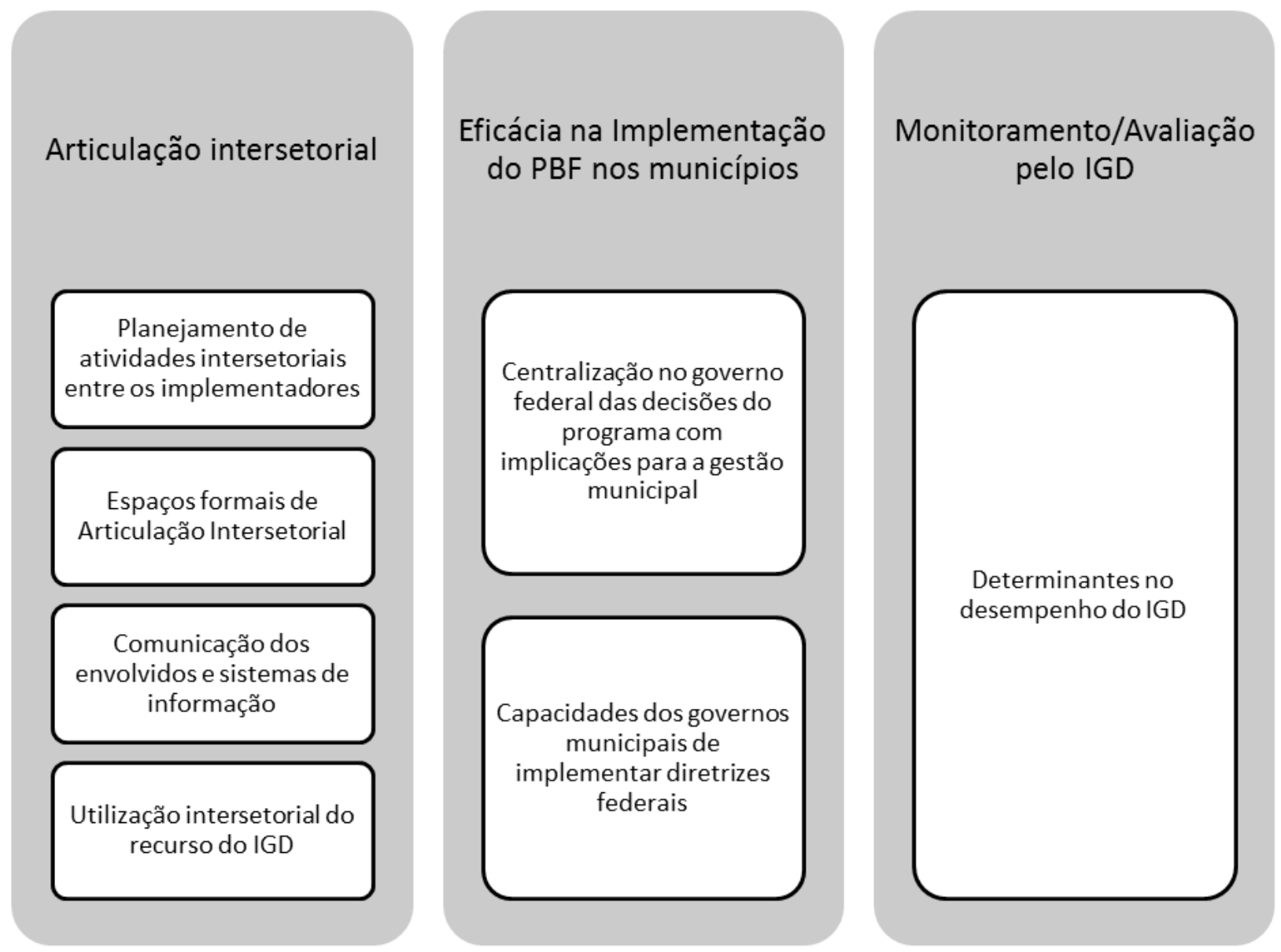

Fonte: Os autores, com base na pesquisa, 2016.

\section{Estudos empíricos que tratam da Articulação Intersetorial na implementação do Programa Bolsa Família}

Entre os trabalhos nota-se um maior número de estudos que abordam a coordenação intersetorial do Programa, evidenciando a relevância da intersetorialidade em sua implementação. Em virtude do envolvimento de diversos agentes nas suas atividades, a ação intersetorial é um dos pontos determinantes no êxito da implementação do PBF. Considerando os trabalhos pesquisados, sete estudos de implementação se concentram no tema da intersetorialidade, ou seja, analisam como se desenvolve a articulação intersetorial nas localidades estudadas e estão sumarizados no Quadro 2. 
Quadro 2 - Estudos de caso sobre a implementação do Programa Bolsa Família que abordaram a intersetorialidade

\begin{tabular}{|c|c|c|c|c|}
\hline & Autor & Localidade & Objetivo geral do trabalho & Foco do estudo gerencial \\
\hline \multirow{6}{*}{ 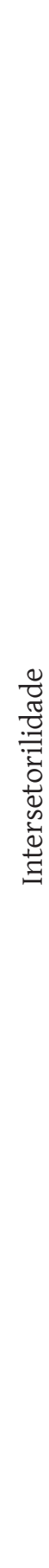 } & $\begin{array}{l}\text { Coelho } \\
(2009)\end{array}$ & Manguinhos (RJ) & $\begin{array}{l}\text { Analisar as possibilidades e } \\
\text { limites de ações intersetoriais } \\
\text { por meio da experiência de } \\
\text { implementação local do PBF em } \\
\text { Manguinhos }\end{array}$ & $\begin{array}{l}\text { Ações de cooperação } \\
\text { intersetorial entre as agências } \\
\text { implementadoras do PBF }\end{array}$ \\
\hline & $\begin{array}{l}\text { Monnerat } \\
\text { (2009) }\end{array}$ & Niterói (RJ) & $\begin{array}{l}\text { Analisar o processo de } \\
\text { implementação descentralizada } \\
\text { das condicionalidades do } \\
\text { Programa Bolsa Família (PBF) no } \\
\text { âmbito do SUS }\end{array}$ & $\begin{array}{l}\text { Descentralização das ações de } \\
\text { condicionalidades de saúde }\end{array}$ \\
\hline & $\begin{array}{l}\text { Santos } \\
(2010)\end{array}$ & Guarulhos (SP) & $\begin{array}{l}\text { Analisar como funciona a } \\
\text { intersetorialidade enquanto } \\
\text { modelo de gestão do PBF, bem } \\
\text { como compreender como são } \\
\text { estabelecidas e mantidas as } \\
\text { relações entre os setores }\end{array}$ & $\begin{array}{l}\text { Mecanismos de } \\
\text { intersetorialidade }\end{array}$ \\
\hline & $\begin{array}{l}\text { Santos } \\
(2011)\end{array}$ & Manguinhos (RJ) & $\begin{array}{l}\text { Analisar a implementação dos } \\
\text { programas complementares } \\
\text { a nível local, identificando as } \\
\text { potencialidades e os entraves } \\
\text { deste processo em Manguinhos, } \\
\text { região localizada na Zona Norte } \\
\text { do município do Rio de Janeiro }\end{array}$ & $\begin{array}{l}\text { Articulação do PBF com Plano } \\
\text { Setorial de Qualificação e } \\
\text { Inserção Profissional (PlanSeQ), } \\
\text { o Programa de Mobilização da } \\
\text { Indústria Nacional de Petróleo } \\
\text { e Gás Natural (PROMINP) } \\
\text { e o Programa Nacional de } \\
\text { Inclusão de Jovens (PROJOVEM) }\end{array}$ \\
\hline & $\begin{array}{l}\text { Filgueiras } \\
\text { (2013) }\end{array}$ & $\begin{array}{l}\text { Nacional (Nível } \\
\text { de gestão federal) }\end{array}$ & $\begin{array}{l}\text { Examinar a colaboração entre } \\
\text { o Ministério da Educação e o } \\
\text { Ministério do Desenvolvimento } \\
\text { Social e Combate à Fome no } \\
\text { Brasil para o acompanhamento } \\
\text { do compromisso assumido pelas } \\
\text { famílias }\end{array}$ & $\begin{array}{l}\text { Articulação entre os atores } \\
\text { institucionais do Governo } \\
\text { Federal na frequência escolar }\end{array}$ \\
\hline & $\begin{array}{l}\text { Trevisani } \\
(2012)\end{array}$ & Rio de Janeiro (RJ) & $\begin{array}{l}\text { Avaliar a implementação da } \\
\text { atenção à saúde às famílias do } \\
\text { PBF para o cumprimento das } \\
\text { condicionalidades da saúde no } \\
\text { município do Rio de Janeiro, } \\
\text { visando relacionar o nível e as } \\
\text { características de implantação ao } \\
\text { cuidado à saúde }\end{array}$ & Estrutura da atenção à saúde \\
\hline
\end{tabular}

Fonte: Os autores, com base na pesquisa, 2016.

A análise procurou destacar quatro elementos que apareceram como determinantes na gestão intersetorial do Programa nas localidades onde as pesquisas ocorreram: I) Planejamento de atividades intersetoriais entre os agentes implementadores; II) Espaços formais de Articulação 
Intersetorial; III) Comunicação dos envolvidos e sistemas de informação; IV) Utilização intersetorial do recurso do IGD.

\section{Planejamento de atividades intersetoriais entre os agentes implementadores do PBF}

A implementação do PBF, em especial a operacionalização das condicionalidades, ocorre em meio a relações intersetoriais e arranjos cooperativos. Considerado fundamental para a integralidade das ações do Programa o planejamento integrado entre os entes envolvidos é um elemento importante em sua implementação. Sobre este aspecto destacam-se os seguintes resultados:

a. Ausência de planejamento formal, em conjunto, entre os implementadores do Programa nos municipios. A gestão intersetorial carece de um planejamento e estratégias conjuntas, ou seja, ela ainda está restrita a ações incrementais e de caráter emergencial (SANTOS, 2011);

b. As relações que promovem ações intersetoriais nos municipios não necessariamente obedecem à hierarquia pré-definida e se concentram principalmente em relações informais entre quadros de médio e baixo escalão (SANTOS, 2011);

c. Prevalece a percepção de que os subsetores, como o setor saúde e educação, são chamados a implementar as condicionalidades sob condições e regras de funcionamento previamente definidas pela assistência social (MONNERAT, 2009);

d. Existe centralização decisória e de processos levando à restrição no acesso às informações dos beneficiários do Programa. Também é percebida uma disputa pela sua coordenação (SANTOS, 2011).

A literatura sistematizada revela uma fraca interação entre os envolvidos na implementação do PBF, o que acarreta uma atividade intersetorial de pouco planejamento - realizado sem participação da alta cúpula de gestores e com ações pouco fundamentais para o Programa, centralização decisória e ausência de negociação com os implementadores das condicionalidades. Portanto, enfatiza-se que essas características levam a um enfraquecimento de formalização das ações, dando a elas perfil pouco profissionalizado.

\section{Espaços formais de Articulação Intersetorial}

Existe uma complexidade em integrar setores e há também indicativo que as ações não se desenvolvem integralmente pela ausência ou escassez de mecanismos indutores como espaços formais para essas negociações. As características mais relevantes encontradas nos resultados desses estudos foram:

a. A viabilização de parcerias e interlocução voltada à construção de iniciativas comuns entre as Secretarias Municipais de Saúde, Educação eAssistência Social como a criação do Grupo Intergestor e o Grupo Descentralizado (COELHO, 2009);

b. Favorecimento de iniciativas da coordenação municipal do PBF pela ação do Comitê Intersetorial organizado para promover iniciativas conjuntas entre as áreas de saúde, assistência social e educação (MONNERAT, 2009);

c. Arenas locais com necessidade de fortalecimento. Técnicos, gestores, lideranças comunitárias e população beneficiária devem ser conduzidos a somar esforços para o fortalecimento de ações intersetoriais (COELHO, 2009); 
d. Relações entre os setores dependem em grande medida do funcionamento de mecanismos formais. A teia de relações interpessoais dependem de eventuais reuniões, conferências e fóruns, que podem ocorrer anualmente ou demorar um tempo ainda maior, o que torna o contato e a troca de experiências entre esses atores muito fraca (SANTOS, 2011).

Os espaços formais para ações integralizadoras do PBF são apresentados sempre como definidores para promoção de ações conjuntas dos grupos que implementam as suas ações. Conforme esses achados, só é possível identificar a relevância do Conselho Intergestor e do grupo descentralizado como ambientes de compartilhamento de experiências e de planejamento de ações articuladas. No âmbito municipal é facultativa a presença de conselho ou grupo formado pelos coordenadores do PBF em diferentes áreas. Na gestão estadual do Programa, a Portaria $\mathrm{n}^{\circ}$ 256, de 10 de Março de 2010, incube o Estado de instituir uma Comissão Intersetorial responsável pelas ações do PBF e do Cadastro Único no âmbito estadual, composta por representantes das áreas do Governo Estadual de Assistência Social, Educação, Saúde, Planejamento e Trabalho.

Não havendo uma institucionalização da prática intersetorial dos municípios por meio dos conselhos, planejamentos integrados inexistem. Dessa forma, conforme relatado nos estudos, as iniciativas intersetoriais se desenvolvem muiito mais por meio de parcerias da rede de relações interpessoais do que por meio das estruturas formais. Isto permite observar que a ausência de espaços formais de negociação têm repercussões negativas para ações de sinergia na implementação do PBF.

\section{Comunicação/sistema de informação}

Os estudos sinalizaram como tópico relevante para ações intersetoriais no Programa a intensificação da comunicação, tendo como ação principal a integração dos sistemas de informação como meio para viabilizar ações integradas. Considera-se que a sobreposição de informações em diferentes sistemas seja um dos elementos que dificulte o planejamento de ações conjuntas. Os sistemas que são utilizados pelas ações do Programa são: Cadastro Único, Sistema de Pagamentos operado pela Caixa Econômica, Sistema de Frequência Escolar do PBF (MEC), Sistema Bolsa Família na Saúde (MS) e o Sistema de Acompanhamento do Programa de Erradicação do Trabalho Infantil. As características mais relevantes encontradas nos estudos foram:

a. Comunicação vertical e horizontal entre os setores e os atores chave locais evidenciou-se frágil. Sistemas de informação apresentaram-se superpostos e não apoiam a integração das ações (COELHO, 2009);

b. Necessidade da abertura dos canais de comunicação com participação dos burocratas do nível de rua, para promover maior integração entre os setores e a horizontalização dos processos em uma gestão intersetorial (SANTOS, 2011).

Conforme evidências desses estudos, a ausência de ambientes virtuais com atualização imediata das informações dos beneficiários do PBF e que integrem as entidades implementadoras apresenta-se como um dificultador para ações integradas, tanto na base operacional como na alta gestão. A própria integração dos sistemas se restringe ao uso do Número de Identificação Social (NIS), não havedo acesso a um banco de dados mais amplo com informações das diferentes esferas.

Para Paiva, Falcão e Bertholo (2013), deve-se considerar que ocorreram avanços nos sistemas de informação do PBF, desde avanços substanciais (criação do Cadastro Único) ou 
incrementais, como o aperfeiçoamento dos aplicativos de informática que eram de modo offline e passaram a ser online. Com essa mudança passou a ser dispensável a instalação, atualização e constante transmissão na base de dados o que dificultava que a informação local fosse exatamente a informação disponibilizada oficialmente. Os autores indicam que uma tentativa de integração dos sistemas é o SISCON (Sistemas de condicionalidades) normatizado pela Instrução Operacional n³3, SENARC/MDS de 2009. Porém, o sistema não realiza a socialização dos dados entre os agentes implementadores.

\section{Aspectos da utilização do recurso do IGD-M por diferentes setores}

O recurso do IGD-M é proporcional a uma média dos sub-indicadores que compõem o fator de operação, gerados isoladamente por cada entidade que implementa o PBF. Dessa forma, a tendência do índice é mensurar a capacidade isolada das ações, pois nenhum componente valoriza a integração das ações. Os resultados mais relevantes sobre este tema foram:

a. No desenho do Programa a estrutura de indução da intersetorialidade encontra-se circunscrita ao incentivo financeiro repassado através do cálculo do Índice de Gestão Descentralizada (IGD) que não vem acompanhado de outros tipos de indução intersetorial (MONNERAT, 2009);

b. Centralização das decisões em torno do uso do IGD na Secretaria de Assistência Social dificulta a consolidação de compromissos entre os diferentes parceiros e setores ligados ao Programa (COELHO, 2009).

Em termos de incentivos, o IGD também apresenta uma desproporção na alocação do repasse financeiro, não sendo proporcional para os agentes implementadores. Ou seja, existe uma centralidade no uso do recurso, pois não é obrigatório o repasse financeiro para todas as entidades que implementam o Programa. Igualmente existe uma dificuldade em padronizar esse repasse, pois nem todos os municípios operam de forma semelhante as responsabilidade do Programa.

As subcategorias relacionadas à intersetorialidade permitem analisar que ainda há o que avançar, em especial, a integração entre setores que é um dos pontos fundamentais para gestão do Programa.

\section{Estudos que tratam da eficácia na implementação do PBF pelo municipios}

Outros estudos verificavam em que medida o PBF estava sendo implementado pela esfera municipal com observância aos objetivos propostos. Ressalta-se que os trabalhos se concentraram em estudos de caso. Entre os principais resultados pode-se destacar os descritos no Quadro 3. 
Quadro 3 - Estudo de casos sobre a implementação do Programa Bolsa Família que abordaram a eficácia na implementação do PBF pelos municípios

\begin{tabular}{|c|c|c|c|c|}
\hline & Autor & Localidade & Objetivo geral do trabalho & Foco do estudo gerencial \\
\hline \multirow{5}{*}{ 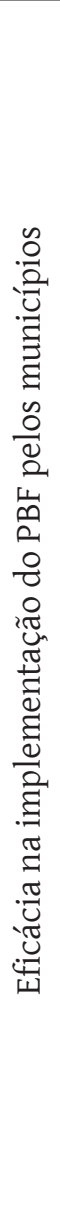 } & Anesi (2010) & $\begin{array}{l}\text { Frederico } \\
\text { Westphalen e } \\
\text { Pelotas (RS) }\end{array}$ & $\begin{array}{l}\text { Discutir as características da gestão } \\
\text { pública do Programa Bolsa Família, } \\
\text { bem como suas repercussões } \\
\text { sociais nos municípios de Frederico } \\
\text { Westphalen e Pelotas, RS }\end{array}$ & $\begin{array}{l}\text { Fiscalização e condução } \\
\text { de planejamento } \\
\text { intersetorial }\end{array}$ \\
\hline & Dias (2008) & Bacabal (MA) & $\begin{array}{l}\text { Avaliar o processo de implementação } \\
\text { do Programa Bolsa Família, no } \\
\text { município de Bacabal no Estado do } \\
\text { Maranhão privilegiando a análise das } \\
\text { condicionalidades estabelecidas pelo } \\
\text { programa no enfrentamento à pobreza }\end{array}$ & $\begin{array}{l}\text { Capacidades das redes } \\
\text { de serviços de educação, } \\
\text { saúde e assistência de } \\
\text { comportar a atividade do } \\
\text { programa e iniciativas } \\
\text { intersetoriais }\end{array}$ \\
\hline & $\begin{array}{l}\text { Ferreira } \\
(2009)\end{array}$ & Manguinhos, (RJ) & $\begin{array}{l}\text { Analisa o processo de implementação } \\
\text { do Programa Bolsa Família na } \\
\text { região de Manguinhos, no que se } \\
\text { refere ao acompanhamento das } \\
\text { ações de saúde um contexto local } \\
\text { marcado por precária infra-estrutura } \\
\text { urbana e dificuldades no acesso aos } \\
\text { equipamentos públicos }\end{array}$ & $\begin{array}{l}\text { Infraestrutura de } \\
\text { serviços relativo as } \\
\text { condicionalidades de } \\
\text { implementa-las }\end{array}$ \\
\hline & $\begin{array}{l}\text { Pertesen } \\
(2007)\end{array}$ & Ijuí (RS) & $\begin{array}{l}\text { Analisar prática municipal em prol da } \\
\text { adesão ao programa }\end{array}$ & $\begin{array}{l}\text { Implementação de ações } \\
\text { básicas do programa }\end{array}$ \\
\hline & Bichir (2011) & $\begin{array}{l}\text { São Paulo (SP) } \\
\text { Salvador (BA) }\end{array}$ & $\begin{array}{l}\text { Identificar os desafios enfrentados } \\
\text { pelo poder central para garantir a } \\
\text { implementação homogênea de um } \\
\text { programa nacional de transferência } \\
\text { condicionada de renda a ser gerido } \\
\text { pelos municípios }\end{array}$ & $\begin{array}{l}\text { Capacidades institucionais } \\
\text { dos governos municipais }\end{array}$ \\
\hline
\end{tabular}

Fonte: Os autores, com base na pesquisa, 2016.

A análise desses trabalhos apresenta dois determinantes principais para eficácia da implementação do PBF pelos municípios: I) Centralização no governo federal das decisões do Programa com implicações para a gestão municipal e II) Capacidades dos governos municipais para implementar diretrizes federais. Os dois componentes são complementares, pois a centralização das decisões do Programa no nível federal é resultante, em parte, das baixas capacidades estatais (técnicas e políticas) de desempenhar as funções inerentes ao Programa.

\section{Centralização no governo federal das decisões do programa com implicações para a gestão municipal}

Um dos pontos fundamentais abordados pelos estudos é a relação entre o governo central e os governos subnacionais e as implicações nas atividades relacionadas ao PBF. A divisão de tarefas onde o governo federal formula e legisla sobre o Programa e os governos locais implementam rebate fortemente nas atividades realizadas. Os principais resultados sobre este aspecto são enumerados pelos estudos da seguinte forma: 
a. Existe uma centralização das decisões na esfera federal. Decisões cruciais, como a decisão de incluir e excluir os beneficiários, por exemplo, cabe ao governo federal e não passa pelos municípios apesar da descentralização da implementação (MONNERAT, 2009);

b. Criação de parâmetros nacionais por meio de normatizações federais sem considerar a realidade local, especialmente, o Cadastro Único de Programas Sociais e os mecanismos de repasses de recursos federais para os municípios representados pelo Índice de Gestão Descentralizada (IGD) restringe o espaço para grandes alterações no momento da implementação do Programa no nível local (BICHIR, 2011);

c. Subliminarmente constituem um entrave para a implementação do PBF as divergências político-partidárias existentes entre os diferentes níveis de governo (PERTESEN, 2007).

Observa-se nos resultados uma centralização das decisões no governo federal, levando a uma uniformização dos mecanismos de monitoramento e controle, pouco aplicável aos contrastes existentes entre os municípios brasileiros. Este fato leva a uma penalização dos municípios com estrutura administrativa mais frágil. Aparece ainda como agravante para assimetria de tomada de decisão a divergência partidária, acentuada pela fragmentação de partidos brasileiros que resulta em governos de coalizão com dificuldades de consenso quanto às suas posturas estratégicas.

Estes pontos devem ser considerados na apreciação e na repercussão das atividades do Programa. O contexto federativo brasileiro é complexo, porém é perceptível a necessidade de se considerar as distintas realidades, principalmente onde o Programa possui maior relevância, ou seja, nas regiões mais pobres do país, onde a estrutura de assistência é também mais precária e onde existe maior número de famílias beneficiárias da ação.

\section{Capacidade dos governos municipais para implementar diretrizes federais}

Por mais elaboradas que sejam as diretrizes do PBF, elas podem ter elevado grau de dificuldade em municípios que não conseguem executa-las dada a capacidade administrativa local, o que pode elevar o grau de centralização da gestão central do Programa. Alguns resultados evidenciam esse condicionante na gestão do PBF:

a. Implementação afetada por diferentes capacidades institucionais disponíveis no plano local e interesse político, não apenas pelo desenho institucional (BICHIR, 2011);

b. As características de cada região afetam significativamente o Programa, em especial os reflexos da gestão municipal, havendo evidências nas condicionalidades da saúde e educação (ANESI, 2010);

c. A velocidade exigida pelos formuladores para implementar o Programa trouxe dificuldades para que os diferentes níveis de governo amadurecessem conhecimento necessário acerca da concepção e desenho operacional do Programa, bem como reunissem as capacidades institucionais necessárias à sua execução (MONNERAT, 2009);

d. A falta de estrutura dos sistemas de serviços sociais em que o PBF é acoplado resulta em déficits de implementação, pois existem desafios próprios do SUS quanto às dificuldades de estruturação da SMAS e do próprio SUAS nos municípios (MONNERAT, 2009);

e. Em municípios menores com poucos recursos, deficiência material e equipes deficientes em capacitação, seu papel se restringe apenas em cumprir um papel meramente de fiscalização (ANESI, 2010); 
f. Ocorre a utilização da estrutura já existente para o acompanhamento das condicionalidades, não havendo mudanças na estrutura de atendimento das famílias beneficiárias pelas instâncias que já atuam, o que resulta em um acompanhamento burocrático das condicionalidades (DIAS. 2008);

g. A falta de recursos financeiros por parte dos municípios somada à precariedade das condições para fiscalização (falta de recursos materiais), implica na precária oferta das condicionalidades (PERTESEN, 2007).

Existem diferenças entre as capacidades institucionais disponíveis para implementação do PBF em cada localidade e essas, por sua vez, são determinadas em parte pelas características da região o que leva à disparidades do modo como se implementa o Programa. Outro fator que leva determinadas localidades a terem menos êxito em sua implementação se dá pelo fato de que sua estruturação ocorre na já deficitária rede de serviços básicos (educação, saúde e assistência social), sem significativos investimentos para o aumento de demanda.

Pela elevada heterogenidade dos locais de implementação do PBF, sua avaliação institucional é um dos princpais pontos de problematização na literatura especializada. A criação de mecanismos de avaliação (IGD-M e IGD-E) para monitorar como os municipios desempenham as atividades obrigatórias do Programa é resultante dessa compreensão.

\section{Estudos que tratam da avaliação e monitoramento na implementação do PBF}

O monitoramento e avaliação da implementação do PBF ocorre principalmente por meio do IGD nas versões IGD-M e IGD-E. O IGD-M, por ter mais tempo em vigor, é explorado pela literatura como indicador da eficácia da implementação do Programa nos municípios sendo composto por meio de uma fórmula que privilegia suas ações básicas. É por meio desse indicador que é repassado o recurso de apoio à gestão do Programa.

Dessa maneira verifica-se que apesar de pouco explorado pela literatura, o IGD apresenta-se como um indicador passível de inferências diversas a respeito do PBF, podendo contribuir para a avaliação de sua eficácia de modo geral e de modo específico, uma vez que os subcomponentes do IGD são taxas relativas a processos básicos do Programa possíveis de isolamento. Os estudos que aprofundam a discussão sobre sua avaliação e o monitoramento são descritos no Quadro 4.

As análises dos estudos se concentram no comportamento dos indicadores do Fator de Operação (principal componente do IGD) perante variáveis do PBF, como número de beneficiários e montante de recursos distribuídos, e a maior parte sinaliza uma gestão mais complexa (sinalizada por menores índices de desempenho do programa) em localidades com maior demanda. 
Quadro 4 - Estudo de casos sobre a implementação do Programa Bolsa Família que abordam a avaliação e monitoramento

\begin{tabular}{|c|c|c|c|c|}
\hline & Autor & Localidade & Objetivo geral do trabalho & $\begin{array}{l}\text { Foco do estudo } \\
\text { gerencial }\end{array}$ \\
\hline \multirow{6}{*}{ 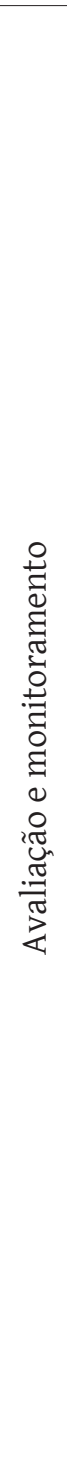 } & $\begin{array}{l}\text { Monteiro; Ferreira } \\
\text { e Teixeira (2009) }\end{array}$ & Minas Gerais & $\begin{array}{l}\text { Analisar a qualidade e os fatores que } \\
\text { determinam a gestão do Programa } \\
\text { Bolsa Família em Minas Gerais }\end{array}$ & $\begin{array}{l}\text { Desempenho dos } \\
\text { índices de avaliação }\end{array}$ \\
\hline & $\begin{array}{l}\text { Pedroso; Du Pin } \\
\text { Calmon e Bandeira } \\
(2009)\end{array}$ & $\begin{array}{l}\text { Capitais } \\
\text { brasileiras }\end{array}$ & $\begin{array}{l}\text { Avaliar a eficiência relativa das } \\
\text { capitais na gestão descentralizada do } \\
\text { Programa Bolsa-Família por meio da } \\
\text { aplicação da Análise } \\
\text { Envoltória de Dados (Data } \\
\text { Envelopment Analysis) }\end{array}$ & $\begin{array}{l}\text { Avaliação e } \\
\text { monitoramento do } \\
\text { programa }\end{array}$ \\
\hline & Monteiro(2008) & Minas Gerais & $\begin{array}{l}\text { Alocação de recursos e eficiência na } \\
\text { gestão do Programa Bolsa Família }\end{array}$ & $\begin{array}{l}\text { Relação de recursos } \\
\text { financeiros com o } \\
\text { desempenho na gestão } \\
\text { do programa }\end{array}$ \\
\hline & $\begin{array}{l}\text { Estrella e Ribeiro } \\
(2008)\end{array}$ & Nacional & $\begin{array}{l}\text { Observar o impacto das } \\
\text { transferências do Bolsa Família } \\
\text { sobre a variação do IGD, controlando } \\
\text { as condições socioeconômicas e } \\
\text { políticas dos municípios atendidos }\end{array}$ & $\begin{array}{l}\text { Fatores interferentes } \\
\text { na gestão do programa } \\
\text { que promovam } \\
\text { alteração no IGD }\end{array}$ \\
\hline & Pizzolato (2014) & Nacional & $\begin{array}{l}\text { Realizar avaliação do desempenho } \\
\text { dos governos municipais em } \\
\text { gerenciar suas novas atribuições e, } \\
\text { para tanto, serão usadas informações } \\
\text { de indicadores de gestão dos } \\
\text { mesmos, referente ao Programa } \\
\text { Bolsa Família, tendo como base o ano } \\
\text { de } 2010\end{array}$ & $\begin{array}{l}\text { Avaliação e } \\
\text { monitoramento do } \\
\text { programa }\end{array}$ \\
\hline & $\begin{array}{l}\text { Monteiro; Silva e } \\
\text { Ribeiro (2014) }\end{array}$ & Bahia & $\begin{array}{l}\text { Avaliar o desempenho da gestão } \\
\text { do Programa Bolsa família (PBF) na } \\
\text { Bahia }\end{array}$ & $\begin{array}{l}\text { Avaliação e } \\
\text { monitoramento do } \\
\text { programa }\end{array}$ \\
\hline
\end{tabular}

Fonte: Os autores, com base na pesquisa, 2016.

Os estudos, apesar do eixo comum de análise (determinantes do desempenho do IGD), usam metodologias diversas para avaliar essas relações e chegam a considerações relevantes e que contribuem para melhor entendimento da implementação da política. Com relação aos determinantes no desempenho IGD, os aspectos dos diversos estudos analisados são: I) municípios menores possuem melhor desempenho no IGD-M, fato que necessita de melhor análise (PIZZOLATO, 2014); II). Os municípios com piores condições socioeconômicas apresentaram melhores resultados para o IGD-M, pois apesar de piores condições econômicas, têm a menor demanda de famílias beneficiárias (ESTRELLA; RIBEIRO, 2008); III) Existe relação negativa entre o aumento da população e famílias beneficiadas e o IGD-M, concluindo que municípios maiores apresentam menores escores de IGD dado que possuem a menor relação de demanda e assistência 
(assistência relativa). (MONTEIRO; FERREIRA E TEIXEIRA, 2009); IV) A melhor qualidade na prestação da informação ocorre justamente para os municípios com indicadores sociais mais frágeis, sendo esses os mais dependentes dos recursos do PBF porém com menor demanda relativa (ESTRELLA; RIBEIRO, 2008);

No caso do PBF a localidade que tiver um melhor desempenho do IGD será reconhecida com maior cobertura do teto do beneficio. Estes índices tendem a se manter pela rotina dos usuários aos serviços. A transferência reflete um incentivo para tornar a unidade cada vez mais capaz de responder às demandas. As localidades que não conseguem o melhor desempenho estabelecerão um círculo vicioso, ou seja, receberão menos recursos e não haverá incentivos para melhorias. Os municípios com baixo desempenho podem manter sempre seus indicadores ruins pelo simples fato da inexistência de alternativas A avaliaçao pelo IGD precisa ser mais estratégica para reduzir fragilidades.

A dificuldade para realizar uma avaliação única para o PBF deriva também das disparidades dos locais onde é implementado. Considera-se o federalismo de grande poder explicativo para o funcionamento do Programa, pois a interação estabelecida entre o governo nacional e os subnacionais interfere no grau de autonomia e recursos, ou seja, variáveis com implicações diretas ao Programa.

\section{Conclusão}

A presente revisão evidencia que apesar da extensa quantidade de trabalhos acerca do Programa Bolsa Família, poucos são os estudos que centram suas atenções em um elemento fundamental para seu sucesso: a implementação. E, assim sendo, deixam de abordar aspectos importantes para a avaliação de sua eficiência, eficácia e efetividade plenas.

A implementação é uma das fases mais críticas de uma política pública. Em especial, quando ela assume carcaterísticas top down com formulação no plano nacional sem que se leve em consideração as particularidades dos municipios de um país continental como o Brasil. Em decorrência dessa compreensão, os estudos se ressentem de aportes teóricos apoiados na ação pública que valoriza o papel dos atores e a dinâmica de interações que configuram a forma como o Programa é percebido e implementado.

Os estudos realizados, de um modo geral, em função do pouco espaço dedicado à implementação invizibilizam a baixa capacidade de gestão dos municípios e as dificuldades gerenciais neste nível de governo. A padronização de condutas pelo governo federal impede que a implementação do Programa se efetive em conformidade com a dinâmica do local ao tempo em que tambem impede que ocorra um ciclo virtuoso de avaliação da implementação. Em decorrência, temas importantes como intersetorialidade, espaços institucionais de articulação, capacidade de gestão, formas de avaliação, integração entre os atores, entre outros, continuam a demandar atenção.

Importa destacar também que pela ausência de uma visão bottom up que privilegia o papel dos atores na condução da política, não se encontrou nenhum trabalho com foco na gestão estadual do Programa. O fato desse nível de govenro não ter sido explorado decorre da exclusividade de atenção dos estudos sobre a relação união e municípios.

E, em uma perspectiva mais geográfica, o Nordeste apesar ser a região numericamente de maior relevância para o Programa tem poucos trabalhos empíricos. Indicando a necessidade de que a implementação também tenha um recorte regional. 
O fato de ser uma política nacionalizada torna imperativo que o programa seja ajustado aos municípios e estados, prevendo-se na formulação mecanismos de compreensão de suas potencialidades e limites.

Os pontos assinalados impõe uma agenda de pesquisa importante para os estudiosos do PBF e os atores envolvidos com a sua operacioanlização. Em especial, uma mudança na forma como a política é compreendida e o papel que os atores municipais e estaduais podem assumir. Urge uma agenda centrada nos déficits de implementação para que o ciclo da política pública possa cumprir o seu objetivo.

$\mathrm{O}$ artigo atingiu assim o seu objetivo na medida em que ao revisar as contribuições téoricas existentes sobre a política social mais importante do Brasil trouxe à tona os diferentes recortes de pesquisa utilizados, as lacunas existentes e, em especial, uma agenda de pesquisa futura.

\section{Referências}

AFONSO, J. R. Novos desafios à descentralização fiscal no Brasil: as políticas sociais e as de transferência de renda. In: XVIII Seminário Regional de Política Fiscal (CEPAL/ILPES). Texto apresentado ao debate. Mimeografado. Fevereiro, 2006.

ANESI, S. A. Diferenças da gestão e as repercussões sociais do Programa Bolsa Família nos municípios de Frederico Westphalen e Pelotas, RS. Dissertação (Mestrado em Política Social) de mestrado. Programa de Pós Graduação em Política Social da Universidade Católica de Pelotas. Pelotas, 2010.

ARAUJO, R. M. Programa de Aquisição de Alimentos (2003-2010): avaliação da implementação pela CONAB no Rio Grande do Norte. Tese (Doutorado em Administração). Programa de Pós Graduação em Administração. Universidade Federal do Rio Grande do Norte. Natal. 2012

ARAUJO. F.R. Capacidades estatais para implementação de políticas públicas em ambientes federativos: o caso do Programa Bolsa Família. Doutorado em Administração. Universidade Federal do Rio Grande do Norte. Natal, 2015.

BICHIR, R. M. Mecanismos federais de coordenação de políticas sociais e capacidades institucionais locais: o caso do Programa Bolsa Família. Tese de doutorado em Sociologia. Tese (Doutorado em Ciência Política).Programa de Pós-Graduação em Sociologia e Ciência Política. Instituto de Estudos Sociais e Políticos. Universidade do Estado do Rio de Janeiro. Rio de Janeiro, 2011.

CAVALCANTE, P. Programa Bolsa Família: descentralização, centralização ou gestão em redes?.Revista do Serviço Público, Brasília v. 60, n. 1, p. 29-46, jan./mar. 2009.

COELHO, A. V. A. G. A construção da Intersetorialidade no Programa Bolsa Família em Manguinhos, no Rio de Janeiro. Dissertação (Mestrado em Saúde Pública). Escola Nacional de Saúde Pública. Rio de Janeiro, 2009.

COUTINHO, D. R. Capacidades Estatais no Programa Bolsa Família: o desafio de consolidação do Sistema Único de Assistência Social. Texto para discussão. Instituto de Pesquisa Econômica Aplicada. Brasília. Rio de Janeiro. 2013.

CURRALERO, C. R. B.; ALONSO, A. F. 0 índice de Gestão Descentralizada (IGD) e o Sistema de Condicionalidades (SICON) como ferramentas de gestão intersetorial do programa Bolsa Família. IV Congresso Consad de Gestão pública. Centro de Convenções Ulysses Guimaraes, Brasília, 25 a 27 de maio de 2011. 
DIAS, M. N. A. O programa Bolsa Família no munícipio de Bacabal-MA: Avaliação do processo de implementação com foco nas condicionalidades. Dissertação (Mestrado em Políticas Públicas). Programa de pós Graduação em Políticas Públicas da Universidade Federal do Piauí. Teresina, 2008

DRAIBE, S. M. Avaliação de implementação: esboço de uma metodologia de trabalho em políticas públicas. In: BARREIRA, M. C. R. N.; CARVALHO M. C. B. (Orgs). Tendências e perspectivas na avaliação de políticas e programas sociais.São Paulo, IEE/PUC-SP, 2001.p.13-42

ESTRELLA, J.; RIBEIRO, L. M. Qualidade da gestão das condicionalidades do Programa Bolsa Família: uma discussão sobre o índice de gestão descentralizada. Revista de Administração Pública, Rio de Janeiro, v. 42, n. 3, p.351-367, Mai./Jun. 2008.

FERREIRA, M. N. Programas de transferência condicionada de renda e acesso aos serviços de saúde: um estudo da experiência do Programa Bolsa Família em Manguinhos. Dissertação (Mestrado em Saúde Pública). Escola Nacional de Saúde Pública Sergio Arouca. Rio de Janeiro, 2009.

FILGUEIRAS, C. A. C. Parceria intersetorial em políticas sociais: o controle da frequência escolar no Programa Bolsa Família, ENAP. Casoteca da Gestão Pública. 2013. 43p.

LíCIO, E. C. A trajetória dos programas de transferência de renda no Brasil: o impacto da variável federativa. Revista do Serviço Público. Brasília, n. 55, v. 3, p.37-59, jul./set, 2004.

LÍCIO, E.C.; MESQUITA, C.S.; CURRALERO, C.R. Desafios para coordenação intergovermental do programa Bolsa Família. Revista de Administração Eletrônica. São Paulo, v.51, n. 5, p.458-470, set./ out. 2011.

MAGALHÃES, R.; BODSTEIN, R. Avaliação de iniciativas e programas intersetoriais em saúde: desafios e aprendizados. Ciênc. saúde coletiva, Rio de Janeiro, v. 14, n. 3, p.,861-868, Jun. 2009.

MESQUITA, C. S. Contradições do processo de implementação de políticas públicas: uma análise do Programa Bolsa Família 2003 - 2006. Revista do Serviço Público. Brasília, n.57, n. 4, p. 465-487, out/ dez. 2006.

MONNERAT, G. L. Transferência condicionada de renda, saúde e intersetorialidade: lições do Programa Bolsa Família. Tese (Doutorado em Saúde Pública). Escola Nacional de Saúde Pública Sergio Arouca. Rio de Janeiro, 2009

MONTEIRO, D. A. A. Alocação de recursos e eficiência na gestão do Programa Bolsa Família. Dissertação (Mestrado em Administração).. Programa de Pos Graduação em Administração. Universidade Federal de Viçosa. Viçosa-MG, 2008.

MONTEIRO, D. A. A.; FERREIRA, M. A. M.; TEIXEIRA, K. M. D. Determinantes da Gestão do Programa Bolsa Família: análise do índice de gestão descentralizada em Minas Gerais. Saúde Sociedade. São Paulo, v.18, n.2, p.214-226, 2009.

MONTEIRO, D. A. A.; SILVA, A. A. P.; RIBEIRO, E. M. Avaliação da Gestão do Programa Bolsa Família na Bahia. Revista Interdisciplinar de Gestão Social, Salvador, v.3 n.3, p.259-255 ,set. / dez. 2014.

PAIVA, L. H.; FALCÃO, T.; BERTHOLO, L. Do Bolsa Família ao Brasil sem Miséria: Um Resumo do Percurso Brasileiro recente na busca da superação da pobreza extrema. In: NERI, M.C; CAMPELLO, T. (Orgs) Programa Bolsa Família: Uma década de inclusão e cidadania. Brasília, IPEA, 2013. p.25-46

PEDROSO, M. M.; DU PIN CALMON, P. C.; BANDEIRA, L. F. O uso da Análise Envoltória de Dados para avaliação da gestão do Programa Bolsa-Família. Comunicação em. Ciências da Saúde. n.20, v.1, p. 3744, 2009. 
PERTESEN, L. L. Implementação do Programa Bolsa Família: uma política social descentralizada. Dissertação (Mestrado em Desenvolvimento Regional) Programa Pós Graduação em Desenvolvimento Regional. Universidade de Santa Cruz do Sul, Santa Cruz do Sul, maio de 2007

PIZZOLATO, B. Desempenho dos municípios na gestão do Programa Bolsa Família: o impacto das características da burocracia local. Dissertação (Mestrado em Administração Pública). Escola de Administração de Empresas de São Paulo. São Paulo, 2014

QUINHÕES, T. A.; FAVA, V. M. D. Intersetorialidade e transversalidade: a estratégia dos programas complementares do Bolsa Família. Revista do Serviço Público. Brasília. n. 61, v.1, p.67-96, Jan/Mar, 2010.

SANTOS, C. R. B. Portas de saída da pobreza: a implementação de programas complementares do Programa Bolsa Família em Manguinhos, Rio de Janeiro. Dissertação (Mestrado em Saúde Pública). Programa de Pós Graduação em Saúde Pública. Escola Nacional de Saúde Pública Sergio Arouca. Rio de Janeiro, 2010

SANTOS, N. N. A intersetorialidade como modelo de gestão das políticas de combate à pobreza no Brasil: o caso do programa Bolsa Família no município de Guarulhos. Dissertação (Mestrado em Administração). Mestrado em Administração Pública e Governo. Fundação Getúlio Vargas de São Paulo. São Paulo, 2011

SILVA, L. A. L. Mecanismos da construção federal da intersetorialidade no Programa Bolsa Família: o papel das burocracias. Revista do Serviço Público. v. 64, v. 3, p.327-350, jul/set. Brasília, 2013.

SILVA, P.L.B; MELO, M.A.B. O processo de implementação de políticas públicas no Brasil: características e determinantes. Caderno no 48. Campinas: Unicamp/Nepp 2000. 17p.

SUBIRATS, J. Análisis de políticas públicas y eficácia de la Administración. Madrid: Ministerio para lasAdministraciones Públicas, 1994.12p.

TREVISANI, J. J. D. Avaliação da Implementação das condicionalidades da saúde do Programa Bolsa Família e seu papel no cuidado à saúde - estudo de caso do município do Rio de Janeiro. Tese (Doutorado e Nutrição). Programa de Pós Graduação de Nutrição em Saúde Coletiva. Universidade de São Paulo. São Paulo, 2012. 